\title{
Kinetics and Mechanism of Oxidation of Phenyl Acetic Acid and DI-mandelic Acid by Permanganate in Acid Medium
}

\section{K.VENKATA RATNAM ${ }^{1 *}$, B. SYAMA SUNDAR ${ }^{2}$ and P.S. RADHAKRISHNA MURTI ${ }^{3}$}

'Department of chemistry, Gitam University, Bengaluru campus, Doddaballpur - 561203, India.

${ }^{2}$ Vice-Chancellor, Yogi Vemana University, Kadapa - 516003, India.

${ }^{3}$ Department of chemistry, T.J.P.S College (PG Courses), Guntur - 522006, India.

*Corresponding author E-mail: vratnam2004@gmail.com

http://dx.doi.org/10.13005/ojc/300238

(Received: February 12, 2014; Accepted: March 04, 2014)

\begin{abstract}
Kinetics of oxidation of phenyl acetic acid and DL- Mandelic acid by potassium permanganate in aqueous acetic acid and perchloric acid mixture reveals that the kinetic orders are first order in oxidant, first order in $\mathrm{H}^{+}$and zero order in substrate for phenyl acetic acid. DL-Mandelic acid exhibits first order in oxidant and zero order in substrate. The results are rationalised by a mechanism involving intermediate formation of mandelic acid in case of Phenyl acetic acid and ester formation with Mn (VII) in case of DL-Mandelic acid. The following order of reactivity is observed: DL-Mandelic acid > Phenyl acetic acid. The high reactivity of DL-Mandelic acid over phenyl acetic acid may be due to different mechanisms operating with the two substrates and benzaldehyde is the final product in both the cases.
\end{abstract}

Key words: Kinetics, Oxidation, Phenyl acetic acid, DL-mandelic acid, Permanganate, Acid medium.

\section{INTRODUCTION}

A survey of literature shows that reports on kinetics of oxidation of Phenyl acetic acid and DL-Mandelic acid by various oxidants are well documented ${ }^{1-22}$. But it clearly indicates that there is no comparative studies on oxidation of Phenyl acetic acid and DL- Mandelic acid under similar conditions by $\mathrm{Mn}(\mathrm{VII})$. Hence to establish the differential reactivity of the above substrates oxidation by $\mathrm{Mn}(\mathrm{VII})$ in acidic medium has been investigated. This was also useful in understanding the differential mechanistic pathways in these oxidations, nature of valence states and role of solvent.

\section{MATERIAL AND METHODS}

Potassium permanganate - BDH (AR) was prepared in doubly distilled water and used as stock solution.

Phenyl acetic acid - BDH (AR) was used without further purification.

DL-mandelic acid - BDH (AR) was used without further purification.

All other chemicals, acids and solvents used in 
these investigations were of analytical reagent grade.

\section{Kinetic method}

The method employed by Tompkins ${ }^{22}$ was used: $5.0 \mathrm{ml}$ aliquots of the reaction solution to $5 \%$ $\mathrm{KI}$ solution acidified with $2 \mathrm{~N} \mathrm{H}_{2} \mathrm{SO}_{4}$ and the liberated iodine was titrated with standard thiosulpahte solution. To reduce aerial oxidation of the acidified iodide solution, the acid concentration was kept low. When possible, the aliquot was titrated immediately after the withdrawl. In fast runs they were titrated in random order. In all the cases the titrations were completed within 10 minutes of the liberation of iodine. The low concentration of the thiosulphate employed necessitated its standardization frequently with standard dichromate.

\section{Product analysis}

Both substrates like Phenyl acetic acid and DL-Mandelic acid are oxidised to give benzaldehyde as the major product. This was identified by $2,4-$ DNP test and its melting point was found to be $234^{\circ} \mathrm{C}$ which matches with known value.

\section{RESULTS AND DISCUSSION}

Kinetics and mechanism of oxidation of phenyl acetic acid and DL mandelic acid by $\mathrm{Mn}(\mathrm{VII})$ in aqueous acetic acid medium in the presence of perchloric acid have been investigated. The kinetics results are given below.

\section{Phenyl acetic acid}

Effect of varying concentration of oxidant on reaction rate

The reactions are found to be first order with respect to the oxidant. The first order nature with respect to oxidant is confirmed from the constancy in the rate constants at different initial concentrations of oxidant. Moreover a plot of log(a$x)$ vs time is linear confirming the first order dependence on oxidant (Table-I).

\section{Effect of varying concentration of substrate on reaction rate}

The dependence on the substrate has been found to be zero order as the first order rate constants do not change with increase in concentration of substrate (Table-I).

\section{Effect of varying concentrations of acid on reaction rate}

The kinetic data relating to changes in rate constants with change in acidity is recorded in TableI. A plot of log $\mathrm{k}$ vs $\log \mathrm{H}^{+}$is linear with unit slope. It appears that the active species is permanganic acid as per the equilibrium.

$\mathrm{H}^{+}+\mathrm{MnO}_{4}^{-} \rightleftharpoons \mathrm{HMnO}_{4}$ leading to unit dependence on acidity.

\section{Effect of change in dielectric constant of the} medium

The effect of change in solvent composition of acetic acid on reaction rate has been investigated. The rate constants are presented in Table-I. The reaction rate increases with decrease in dielectric constant. A plot of log k vs D-1/2D+1 $1^{23,24}$ is linear. This shows that these are essentially dipolar - dipolar reactions with the proviso that specific solvent influences like micro dielectric constant at the reaction site, molecular cohesion and other factors like solute - solvent interactions are operating in these reactions finally leading to increase in rate with decrease in dielectric constant.

\section{Effect of addition of salts}

The effect of addition of salts like $\mathrm{Mn}^{++}$and $\mathrm{NaF}$ has been investigated (Table-I). Retardation has been observed with both the salts. The reduction observed with $\mathrm{Mn}^{++}$is due to the reduction of effective concentration of $\mathrm{MnO}$ as per the equation

$$
4 \mathrm{Mn}(\mathrm{II})+\mathrm{Mn}(\mathrm{VII}) \rightarrow 3 \mathrm{Mn}(\mathrm{IV})+\mathrm{Mn}(\mathrm{III})
$$

This indicates that the main oxidant species is $\mathrm{Mn}(\mathrm{VII})$. The retardation observed with $\mathrm{F}^{-}$ normally is attributed to the presence of competing intermediate species like $\mathrm{Mn}(\mathrm{IV})$ or $\mathrm{Mn}(\mathrm{III})$. But the higher retardation with $\mathrm{Mn}^{++}$shows preferentially the main species is $\mathrm{Mn}(\mathrm{VII})$ with the other oxidation states like $\mathrm{Mn}(\mathrm{IV})$ or $\mathrm{Mn}(\mathrm{III})$ being comparatively less in concentration.

\section{DL- Mandelic acid}

Effect of varying concentration of oxidant on reaction rate

The reactions are found to be first order with respect to the oxidant. The first order nature 
with respect to oxidant is confirmed from the constancy in the rate constants at different initial concentrations of oxidant. Moreover a plot of log (a-x) vs time is linear confirming the first order dependence on oxidant (Table-II).

\section{Effect of varying concentration of substrate on reaction rate}

The dependence on the substrate appears to be zero order at all concentrations of substrate as forty fold increase in concentration of the substrate results in 3-fold increase only in reaction rate. This points out that the reaction is apparently of zero order in substrate as found with phenyl acetic acid (Table-II).

\section{Effect of varying concentrations of acid on reaction rate}

The effect of variation of $\mathrm{H}^{+}$in this oxidation could not be studied due to the enormous fastness of reaction with increasing acidity.

\section{Nature of oxidation states of manganese}

Manganese exhibits a variable oxidation number. Oxidation states of manganese i.e. $+2,+4$ and +7 , are stable over wide range of acidity. In basic solution $\mathrm{Mn}(\mathrm{VI})$ and $\mathrm{Mn}(\mathrm{IV})$ are the main species of manganese.

The redox potentials are given below to give a comparative account of valency changes of manganese. However, the overall potential of $\mathrm{Mn}(\mathrm{VII})$ to $\mathrm{Mn}(\mathrm{II})$ change is $1.51 \mathrm{~V}$.

$\mathrm{Mn}(\mathrm{VII})-\mathrm{Mn}(\mathrm{VI}) \mathrm{e}+\mathrm{MnO}_{4}^{-} \rightarrow \mathrm{MnO}_{4}^{2-}+0.558 \pm 0.002$

$\mathrm{Mn}(\mathrm{VI})-\mathrm{Mn}(\mathrm{V}) \mathrm{e}+\mathrm{MnO}_{4}^{2-} \rightarrow \mathrm{MnO}+0.285 \pm 0.001$

$\mathrm{Mn}(\mathrm{III})-\mathrm{Mn}(\mathrm{II}) \quad \mathrm{e}+\mathrm{Mn} \rightarrow \mathrm{Mn}+1.51$

In the present investigation it appears that the two electron change in the rate determining step is important followed by fast changes of $\mathrm{Mn}(\mathrm{V})$ leading to finally $\mathrm{Mn}(\mathrm{II})$ in acid medium.

Mechanistic pathway of oxidation of Phenyl acetic acid

The kinetic orders observed are first order in oxidant, first order in $\mathrm{H}^{+}$and zero order in substrate. The initial reaction appears to be intermediate formation of mandelic acid which decomposes to give benzaldehyde in fast step.

\section{RATE LAW}

$$
\begin{aligned}
& {\left[\mathrm{MnO}_{4}^{-}\right]+\left[\mathrm{H}^{-}\right] \quad \mathrm{HMnO}_{4}} \\
& \begin{array}{lll}
\mathrm{HMnO}_{4}+[\mathrm{S}] & & \text { Complex } \\
\text { Complex } & \stackrel{\text { sow }}{\mathrm{k}} & \text { Products }
\end{array} \\
& \text { Rate }=\mathrm{k} \times[\mathrm{c}] \\
& =\quad \mathrm{k} \times \mathrm{K}_{\mathrm{t}} \times\left[\mathrm{HMnO}_{4}\right][\mathrm{S}] \\
& {\left[\mathrm{HMnO}_{4}\right]_{\mathrm{T}}=\left[\mathrm{HMnO}_{4}\right]+[\mathrm{C}]} \\
& =\left[\mathrm{HMnO}_{4}\right]+\mathrm{K}_{\mathrm{t}}\left[\mathrm{HMnO}_{4}\right][\mathrm{S}] \\
& =\left[\mathrm{HMnO}_{4}\right]+\left[1+\mathrm{K}_{\mathrm{t}}[\mathrm{S}]\right] \\
& {\left[\mathrm{HMnO}_{4}\right]=\frac{\left[\mathrm{HMnO}_{4}\right]_{\mathrm{T}}}{1+\mathrm{K}_{1}[\mathrm{~S}]}}
\end{aligned}
$$

Substitute equation (2) in equation (1), we get

$$
\begin{aligned}
& =\frac{\mathrm{k} \times \mathrm{K}_{1}\left[\mathrm{HMnO}_{4}\right]_{\mathrm{T}}[\mathrm{S}]}{1+\mathrm{K}_{1}[\mathrm{~S}]} \\
& \text { Rate }=\frac{\mathrm{k} \times \mathrm{K}_{1} \times \mathrm{K} \times\left[\mathrm{MnO}_{4}^{-}\right]\left[\mathrm{H}^{+}\right][\mathrm{S}]}{1+\mathrm{K}_{1}[\mathrm{~S}]}
\end{aligned}
$$

The reaction sequence can be represented as follows

$$
\begin{gathered}
{[\mathrm{MnO}]+\left[\mathrm{H}^{+}\right] \stackrel{\mathrm{K} \searrow}{\rightleftharpoons} \mathrm{HMnO}_{4}} \\
\mathrm{HMnO}_{4}+[\mathrm{S}] \stackrel{\mathrm{K}_{1} \searrow \text { Complex }}{\rightleftharpoons}
\end{gathered}
$$

\section{The final product is benzaldehyde}

The sequence given above indicates that the rate determining step involves a two electron loss leading to a carbonium ion which rapidly reacts with water to give mandelic acid initially. Mandelic 

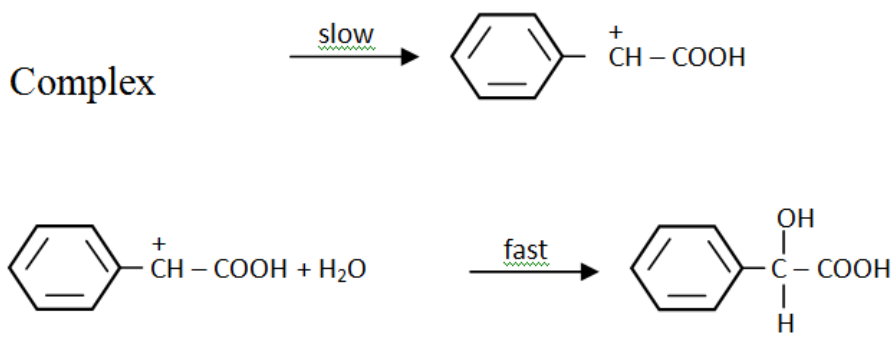<smiles>O=C(O)C(O)c1ccccc1</smiles>

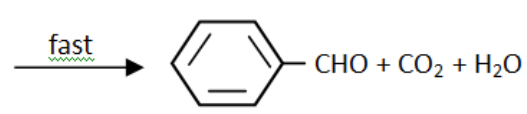

Table 1: Effect of variation of various constituents on reaction rate of Phenyl acetic acid

\begin{tabular}{|c|c|c|c|}
\hline Variant & $\begin{array}{l}\text { Concentration of } \\
\text { Non variant }\end{array}$ & $\begin{array}{l}\text { Concentration of } \\
\text { Variant }\end{array}$ & $k \times 10^{3}\left(\sec ^{-1}\right)$ \\
\hline \multirow[t]{4}{*}{$\mathrm{KMnO}_{4}$} & {$[$ Phenyl acetic acid $]=0.01 \mathrm{M}$} & $0.000125 \mathrm{M}$ & 0.94 \\
\hline & {$\left[\mathrm{HClO}_{4}\right]=0.01 \mathrm{M}$} & $0.00025 \mathrm{M}$ & 1.08 \\
\hline & $\mathrm{AcOH}=20 \%$ & $0.00050 \mathrm{M}$ & 0.91 \\
\hline & Temp. $=40^{\circ} \mathrm{C}$ & & \\
\hline \multirow[t]{4}{*}{ Phenyl acetic acid } & {$\left[\mathrm{KMnO}_{4}\right]=0.00025 \mathrm{M}$} & $0.0025 \mathrm{M}$ & 1.23 \\
\hline & {$\left[\mathrm{HClO}_{4}\right]=0.01 \mathrm{M}$} & $0.005 \mathrm{M}$ & 1.06 \\
\hline & $\mathrm{AcOH}=20 \%$ & $0.01 \mathrm{M}$ & 1.08 \\
\hline & Temp. $=40^{\circ} \mathrm{C}$ & $0.02 \mathrm{M}$ & 1.09 \\
\hline \multirow[t]{4}{*}{$\mathrm{HClO}_{4}$} & {$[$ Phenyl acetic acid $]=0.01 \mathrm{M}$} & $0.0025 \mathrm{M}$ & 0.10 \\
\hline & {$\left[\mathrm{KMnO}_{4}\right]=0.00025 \mathrm{M}$} & $0.0050 \mathrm{M}$ & 0.31 \\
\hline & $\mathrm{AcOH}=20 \%$ & $0.01 \mathrm{M}$ & 1.08 \\
\hline & Temp. $=40^{\circ} \mathrm{C}$ & $0.02 \mathrm{M}$ & 1.80 \\
\hline \multirow[t]{4}{*}{$\mathrm{AcOH}$} & {$[$ Phenyl acetic acid $]=0.01 \mathrm{M}$} & $10 \%$ & 0.28 \\
\hline & {$\left[\mathrm{KMnO}_{4}\right]=0.00025 \mathrm{M}$} & $20 \%$ & 1.08 \\
\hline & {$\left[\mathrm{HClO}_{4}\right]=0.01 \mathrm{M}$} & $30 \%$ & 1.62 \\
\hline & Temp. $=40^{\circ} \mathrm{C}$ & & \\
\hline
\end{tabular}

Table 2: Effect of variation of various constituents on reaction rate of DL-Mandelic acid

\begin{tabular}{llll}
\hline Variant & $\begin{array}{l}\text { Concentration of } \\
\text { Non variant }\end{array}$ & $\begin{array}{l}\text { Concentration of } \\
\text { Variant }\end{array}$ & $\mathbf{k} \times \mathbf{1 0}^{\mathbf{3}}\left(\mathbf{s e c}^{-1}\right)$ \\
\hline $\mathrm{KMnO}_{4}$ & {$[\mathrm{DL}-M a n d e l i c$ acid $]=0.01 \mathrm{M}$} & $0.000125 \mathrm{M}$ & 10.1 \\
& {$\left[\mathrm{HClO}_{4}\right]=0.01 \mathrm{M}$} & $0.00025 \mathrm{M}$ & 10.2 \\
& $\mathrm{AcOH}=20 \%$ & $0.00050 \mathrm{M}$ & 10.5 \\
& $\mathrm{Temp}^{2}=40^{\circ} \mathrm{C}$ & & \\
$\mathrm{DL}-$ Mandelic acid & {$\left[\mathrm{KMnO}_{4}\right]=0.00025 \mathrm{M}$} & $0.00025 \mathrm{M}$ & 3.65 \\
& {$\left[\mathrm{HClO}_{4}\right]=0.01 \mathrm{M}$} & $0.0005 \mathrm{M}$ & 5.23 \\
& $\mathrm{AcOH}=20 \%$ & $0.01 \mathrm{M}$ & 10.2 \\
& Temp. $=40^{\circ} \mathrm{C}$ & & \\
\hline
\end{tabular}


acid is rapidly oxidised to give benzaldehyde which is the final product.

\section{Mechanistic pathway of oxidation of DL-Mandelic} acid

In the present investigation mandelic acid undergoes oxidative decarboxylation to give benzaldehyde. In acid medium permanganate functions as a two electron oxidant. Hence the ionic pathway through ester formation is preferred. In this connection a comment on the oxidation of mandelic acid by acid permanganate at $\mathrm{pH} 4.3$ by earlier workers $^{25}$ is necessary. At pH 4.3 the authors postulated a mechanism involving one electron loss leading to radical formation. It is suggested that acid permanganate essentially reacts through a two electron transfer leading to an ionic pathway. It is only in alkaline medium a one electron loss is postulated in permanganate oxidations. It is difficult to arrive at any of the three types of decarboxylation with ionic path way on the basis of kinetic data alone. In the present investigation the pathway is as follows.

$$
\begin{aligned}
& \text { Oxidant }+\mathrm{S} \rightleftharpoons \text { Ester } \\
& \text { Ester } \longrightarrow \text { Products }
\end{aligned}
$$

The above reactions are represented as follows:

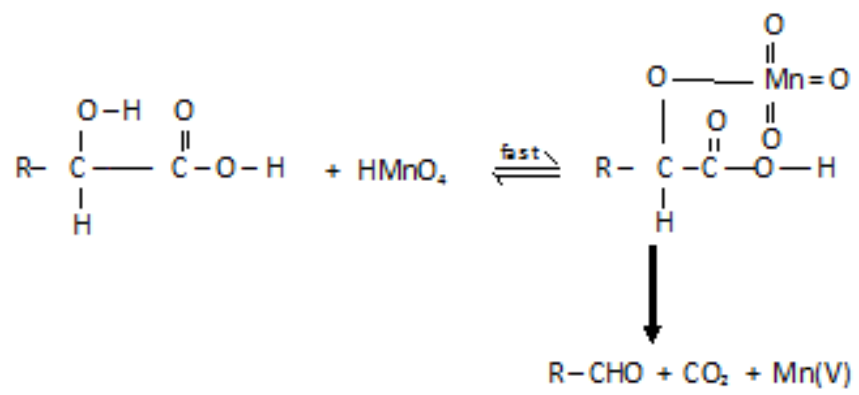

Comparison of oxidation of phenyl acetic acid and Mandelic acid

Mandelic acid reacts much faster than phenyl acetic acid. The presence of hydroxy group helps in simultaneous oxidation and decarboxylation leading to faster rate. Phenyl acetic acid undergoes initial slow oxidation to mandelic acid which later is oxidized rapidly to benzaldehyde.
The corresponding rate constants are $1.08 \times 10^{3}$ $\mathrm{sec}^{-1}$ and $10.22 \times 10^{3} \mathrm{sec}^{-1}$ for phenyl acetic acid and mandelic acid respectively. The high reactivity of mandelic acid over phenyl acetic acid may be due to different mechanisms operating with the two substrates. The former may be passing through a rate determining $\mathrm{O}-\mathrm{H}$ bond cleavage through ester formation and the latter by $\mathrm{C}-\mathrm{H}$ bond fission.

\section{REFERENCES}

1. Trahnovsky,W.S.; Cramer, J.; and Brixius , D.W. J.Am.Chem. Soc. 1974; 96, 1078.

2. Ramanandasarma, Y.; Rajanna,K.C.; Saiprakash, P.K. Indian J.Chem. 1980; 19A, 872.

3. Vausdevan,R.; Subramanian, P.S.; Mathai, I.M. J.Indian.Chem.Soc. 1984; 61,395.

4. .Pati,S.C.; Pathy, H.P.; Dev, B.R. Proc.Indian. Natn.Acad. 1985; 51,853.
5. Venkata Subramanian, N.; Sundaram,S.; Curr. Sci. 1964; 33, 646.

6. Venkata Subramanian, N.; Sundaram,S.; Curr. Sci.1965; 34, 662.

7. Banerji, K.K.; Indian. J.Chem. 1977; 15A, 675.

8. Banerji, K.K.; Indian. J. Chem. 1979; 17A, 904.

9. Malkani, A.K.; Suresh, K.S.; Bakore,G.V. J.Indian.Chem.Soc.1978; LV, 215 - 219. 
10. Venakat Subramanian, N.; Sundaram, S.; Swaminathan, Indian.J.Chem.1975; 13, 1163.

11. Barker, I.R.L.; Aukett, P.J.J.Chem.Soc., PerkII, 1973; 965.

12. Natarajan, R.; Venakata Subramanian, N.; Indian.J.Chem. 1975; 13, 261.

13. Kuselan, P.; Venkata Subramanian,N. Indian. J.Chem. 1983; 22A, 292.

14. Radhakrishnamurti, P.S.; Rath, N.K.; Panda R.K. Indian.J.Chem. 1988; 27A, 407.

15. Brahmaiah; Manikyamba, P.; Indian.J.Chem. 1995; 34(A): 900.

16. Chandraiah, U.; Murthy, C.P.; Sushma Kandlikar, Indian.J.Chem.1989; 28A, 162.

17. VeeraSomaiah, P.; BalReddy, K.; Navaneetha
Rao,T. Indian.J.Chem. 1988; 27A, 876.

18. Balji Kawle; Thirupathi Rao, M.; Adinarayana, M. Inidan.J. Chem. 1994; 33A, 1021.

19. Issifou. Kouadio; Louis J.Kirschembaum; Raj.N.Mehrotra; Yunfusun., J. Chem. Soc., Perkin Trans 1990; 2, 2123.

20. Donald G.Lee ; Taochen. J.Org.Chem., 1991; 56: 5341.

21. Sanjeeva Reddy, Ch.; Vijaya Lakshmi,T. Indian.J.Chem. 1998; 37A: 91.

22. Tompkins, F.C.; Trans. Faraday Soc. 1942; 38: 131.

23. Amis, E.S.; J. Chem. Ed. 1953; 30: 351.

24. Amis, E.S.; Anal. Chem. 1955; 27: 1672.

25. Bakore, G.V.; Rama Shankar;Urmila Goyal.; Indian J.Chem. 1963; 1: 331. 